\title{
Two Highly Effective Phase-Transfer Catalysts for the Enantioselective Synthesis of $\alpha$-Amino Acid Derivatives
}

\author{
Barry Lygo* and Douglas J. Beaumont
}

\begin{abstract}
In this paper we review our recent studies into the phase-transfer catalysed asymmetric alkylation of glycine imines using quaternary ammonium salt catalysts derived from dihydrocinchonidine and $\alpha$-methylnaphthylamine.
\end{abstract}

Keywords: Alkylation · Amino acid · Asymmetry · Catalysis

\section{Introduction}

The enantioselective alkylation of glycine imines such as $\mathbf{1}$ using chiral phase-transfer catalysts (PTCs) offers a simple means of preparing a wide range of $\alpha$-amino acid derivatives 2 (Scheme 1).

This process was pioneered by O'Donnell et al., who demonstrated that $\mathrm{N}$-benzyl derivatives of cinchona alkaloids, e.g. 3 (Fig. 1) could serve as effective catalysts in this reaction, and also identified the tert-butyl ester benzophenone imine of glycine $\mathbf{1}$ as the optimal substrate. Alkylation of this substrate was achieved using a two-phase reaction system comprising of an organic solvent (dichloromethane or dichloromethane/toluene mix) in conjunction with aqueous sodium hydroxide, and resulted in products 2 (Scheme 1) with enantioselectivities of up to $66 \%$. ${ }^{[1]}$

\footnotetext{
${ }^{*}$ Correspondence: Prof. B. Lygo

School of Chemistry

University of Nottingham

Nottingham

NG7 2RD

UK

Tel. +441159513526

Fax +44 1159513564

E-Mail: b.lygo@nottingham.ac.uk
}

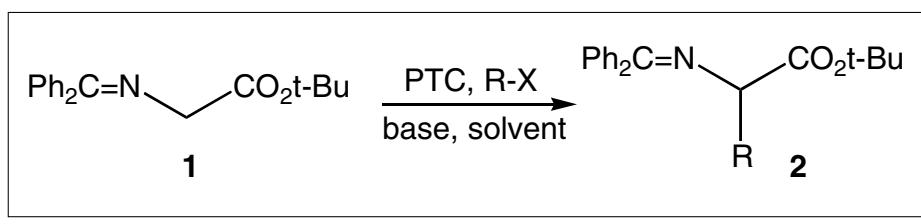

Scheme 1.

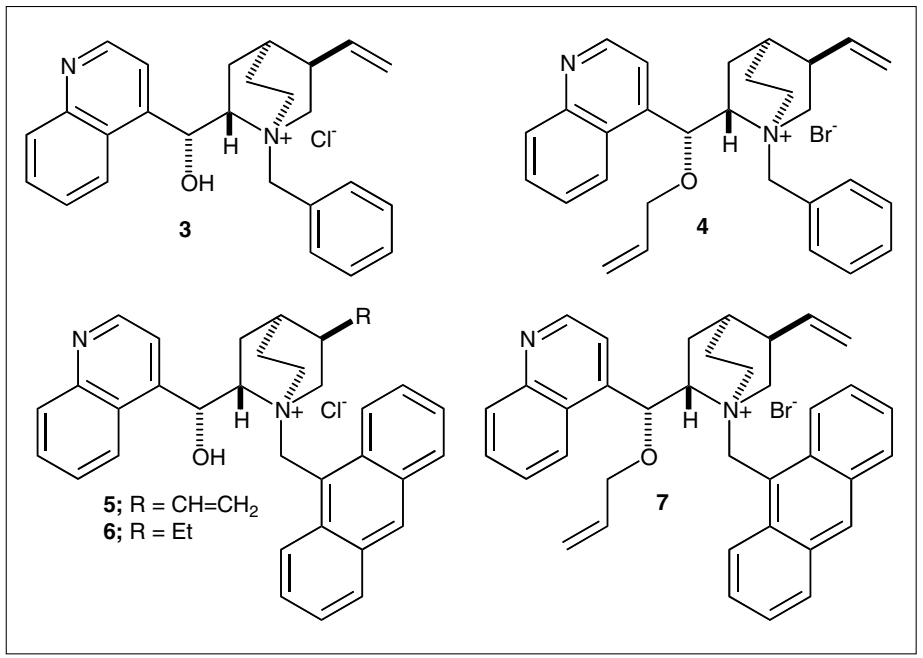

Fig. 1.

Further studies by O'Donnell et al. established that quaternary ammonium salt $\mathbf{3}$ was in fact a pre-catalyst which underwent rapid $\mathrm{O}$-alkylation under the reaction conditions. This observation led to development of the related PTC 4, which delivered enantioselectivities of up to $81 \%$ in the alkylation of imine 1. ${ }^{[2]}$

Subsequent to this, the closely related catalysts 5, 6 and 7 were introduced by ourselves ${ }^{[3]}$ and Corey et al. ${ }^{[4]}$ respectively. A key feature of these new structures was the incorporation of an $\mathrm{N}$-anthracenylmethyl group which resulted in improved enantioselectivities in the alkylation of imine $\mathbf{1}$ (typically $>90 \% e e$ ). A further modification of note was incorporation of the 10,11-dihydroalkaloid in catalyst $\mathbf{6}$, which serves to further enhance the enantioselectivity of alkylation. ${ }^{[5]}$ Typical results obtained using catalysts 3-7 are shown in Table 1.

These examples give an indication of how the level of enantioselectivity varies with catalyst structure and illustrate the 
Table 1. Asymmetric C-benzylation of imine $\mathbf{1}$ using cinchonidine-derived PTCs 3-7

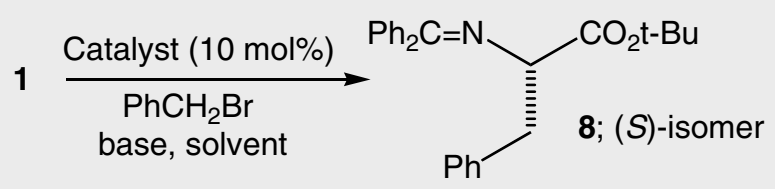

\begin{tabular}{|c|c|c|c|c|c|}
\hline PTC & Base & Solvent & Temp. $\left[{ }^{\circ} \mathrm{C}\right]$ & Yield [\%] & ee [\%] \\
\hline $3^{a}$ & $50 \%$ aq. $\mathrm{NaOH}$ & $\mathrm{CH}_{2} \mathrm{Cl}_{2}$ & 25 & 85 & 64 \\
\hline 4 & & $\mathrm{PhMe} / \mathrm{CH}_{2} \mathrm{Cl}_{2}$ & 5 & 87 & 81 \\
\hline $5^{a}$ & $50 \%$ aq. $\mathrm{KOH}$ & $\mathrm{PhMe}$ & 25 & 74 & 91 \\
\hline 5 & $\mathrm{KOH} / \mathrm{Kaolin}$ & $\mathrm{PhMe} / \mathrm{CHCl}_{3}$ & 20 & 91 & 89 \\
\hline $5^{\mathrm{b}}$ & $1 \mathrm{M}$ aq. $\mathrm{KOH}$ & none & 0 & 96 & 85 \\
\hline $5^{\mathrm{b}}$ & & none $e^{c}$ & 5 & 99 & 87 \\
\hline $6^{a}$ & $50 \%$ aq. $\mathrm{KOH}$ & $\mathrm{PhMe}$ & 25 & 85 & 94 \\
\hline 7 & $\mathrm{CsOH} . \mathrm{H}_{2} \mathrm{O}$ & $\mathrm{CH}_{2} \mathrm{Cl}_{2}$ & -78 & 87 & 94 \\
\hline 7 & BEMP & $\mathrm{CH}_{2} \mathrm{Cl}_{2}$ & -78 & 88 & 91 \\
\hline
\end{tabular}

${ }^{a}$ Active catalyst is the corresponding O-benzyl derivative formed in situ; ${ }^{\mathrm{b}} 1 \mathrm{~mol} \%$ catalyst used; ${ }^{\mathrm{C}} 5$ equiv. $\mathrm{PhCH}_{2} \mathrm{Br}$ used.

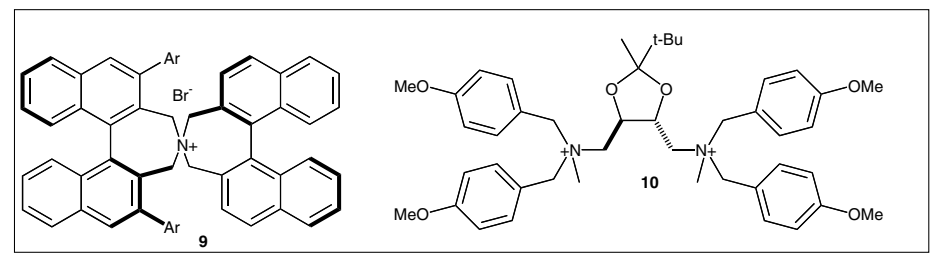

Fig. 2.

range of alkylation conditions that can be employed. Liquid-liquid PTC conditions (entries 1-3,7) tend to be the least reactive, and so are generally employed at or around ambient temperature, whereas solid-liquid conditions (entries 4, 8) can allow alkylation to be performed at lower temperatures, particularly when reactive metal hydroxides such as $\mathrm{CsOH}$ are employed. Interestingly it is also possible to perform the asymmetric alkylation in the absence of an organic solvent (entries 5, 6), ${ }^{[7,8]}$ and also under homogeneous reaction conditions when BEMP is employed as the base (entry 9). ${ }^{[9]}$

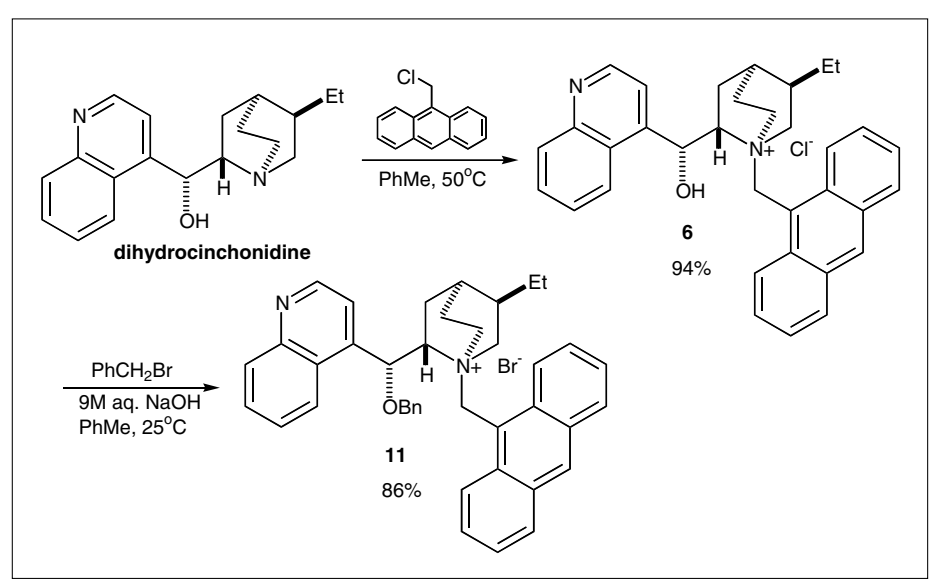

Scheme 2
This allows for considerable scope in the optimization of a given alkylation reaction.

Since the publications describing catalysts 5-7, a range of other cinchona alkaloid derived PTCs have been shown to give high enantioselectivities in the alkylation of imine 1. ${ }^{[10]}$ In addition, a number of highly effective non-alkaloid derived quaternary ammonium salt catalysts have also been developed, perhaps most notable amongst these being the binaphthyl-derived salts 9, ${ }^{[11]}$ and the tartrate-derived salt 10 (Fig. 2). ${ }^{[12]}$

This means that there is now an impressive array of quaternary ammonium salt catalysts available for asymmetric alkylation reactions of imine 1, ${ }^{[13-15]}$ and in this paper we focus on two examples that have been widely employed in our laboratories.

\section{N-Anthracenylmethyl-O-benzyl- 10,11-dihydrocinchonidinium bromide (11)}

Initially our research group focused on the use of the pre-catalysts $\mathbf{5}$ and $\mathbf{6}$, and the corresponding O-benzyl derivative 11. ${ }^{[16]}$ These catalysts are undemanding to prepare (1-2 steps from cinchonidine or dihydrocinchonidine, Scheme 2), ${ }^{[5,17,18]}$ and are capable of delivering a range of $\alpha$-amino acid tert-butyl esters 12 with high enantioselectivities under operationally simple reaction conditions (Table 2).

In most cases the nature of the O-alkyl group incorporated into pre-catalysts $\mathbf{5}$ and 6 has little influence on the outcome of the

Table 2. Asymmetric C-alkylation of imine $\mathbf{1}$ using PTCs $\mathbf{6}$ and $\mathbf{1 1}$

\begin{tabular}{|c|c|c|c|}
\hline 1 & $\begin{array}{l}\mathrm{OH} \\
(10 \mathrm{~mol} \%)\end{array}$ & $\mathrm{H}_{2} \mathrm{~N}_{12}$ & $\mathrm{O}_{2} \mathrm{t}-\mathrm{Bu}$ \\
\hline 1 & $\mathrm{X}, 25^{\circ} \mathrm{C}$ & 12 言 & \\
\hline & $\begin{array}{l}\text { citric acid, } \\
\text { C }\end{array}$ & & \\
\hline $\mathbf{R X}$ & Catalyst & Yield 12 [\%] & ee [\%] \\
\hline $\mathrm{PhCH}_{2} \mathrm{Br}$ & 5 & 76 & 91 \\
\hline & 6 & 85 & 94 \\
\hline & 11 & 85 & 94 \\
\hline 4-Br- $\mathrm{C}_{6} \mathrm{H}_{4}$ & & 80 & 94 \\
\hline (2-Naphth & & 83 & 93 \\
\hline $\mathrm{CH}_{2}=\mathrm{CHC}$ & & 87 & 92 \\
\hline $\mathrm{CH}_{2}=\mathrm{C}(\mathrm{Cr}$ & & 78 & 94 \\
\hline & & 69 & $98^{\mathrm{a}}$ \\
\hline$n$-Bul & & 78 & 93 \\
\hline
\end{tabular}


alkylation, ${ }^{[5]}$ however we have observed occasions when the O-alkyl substituent significantly reduces the catalyst solubility. This can result in incomplete reaction or reduced asymmetric induction, $[19,20]$ and so in these instances use of catalyst $\mathbf{1 1}$ is preferable. It is also possible to generate catalysts such as $\mathbf{1 1}$ in situ, allowing for simple screening and optimization of the catalyst structure for a given alkylation process.[21]

In early studies using catalysts 5, 6 and 11, we employed $50 \%$ aqueous potassium hydroxide as the base, but have since found that $9 \mathrm{M}$ aqueous hydroxide is usually sufficient. This has the advantage of suppressing catalyst decomposition, and also improves tolerance of hydroxide-sensitive functionality within the alkylating agents. ${ }^{[22]}$ This latter aspect was exploited in a key step in the synthesis of the potent glutamate agonist, neodysiherbaine (Scheme 3), ${ }^{[23]}$ in which the allyl iodide 13 was employed as the alkylating agent. Both allylic iodide and acetate functionalities were stable towards hydrolysis under the PTC conditions, enabling the amino acid ester 14 to be generated with high diastereoselectivity and in high overall yield.

The ability of hydroxide-sensitive functionality to survive PTC alkylation reactions of this type is almost certainly due to the fact that most quaternary ammonium salts do not seem to extract hydroxide ion into the organic reaction phase to any significant extent. ${ }^{[24]}$ Thus, for PTC alkylations to be successful, initial deprotonation of the substrate needs to take place either in the basic phase, or at the interface between the two phases.

This precise details of how this occurs are likely to be dependant on the nature of the catalyst and two reaction phases, ${ }^{[2]}$ but in the case of imine $\mathbf{1}$ in toluene, we have been able to show that initial deprotonation of the substrate using 50\% aqueous $\mathrm{KOH}$ (or $40 \%$ aqueous KOD) occurs rapidly in the absence of a PTC, ${ }^{[25]}$ whereas the alkylation step needs the catalyst to be present in order to proceed. This suggests that under these conditions, the main role of the catalyst is to extract the enolate into the organic phase thus facilitating reaction with the alkyl halide. A simple description of these events is depicted in Scheme 4.

A number of catalyst-enolate ion-pair models have been proposed to account for the enantioselectivity observed in imine alkylations involving cinchona alkaloid derivatives, ${ }^{[4,5,26]}$ but in the case of catalyst 11, we favour the arrangement depicted in Fig. 3. This model has been challenged by incorporating a wide range of modifications into the alkaloid structure, ${ }^{[5,27]}$ and all results obtained to date are consistent

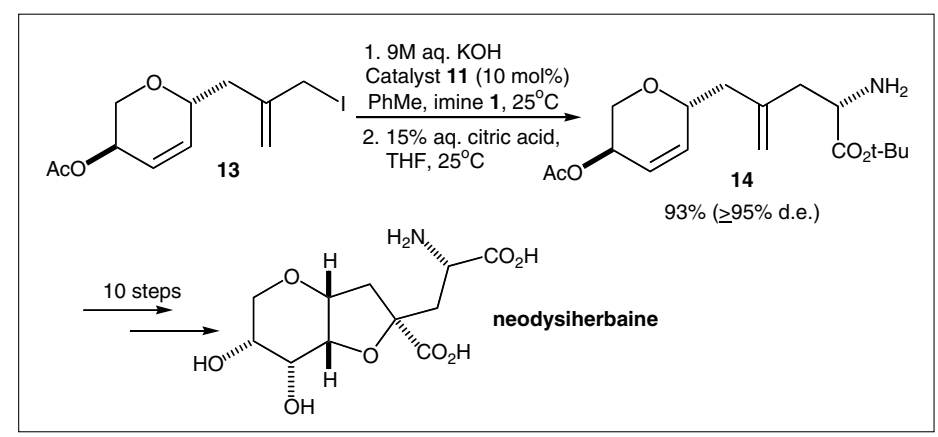

Scheme 3.

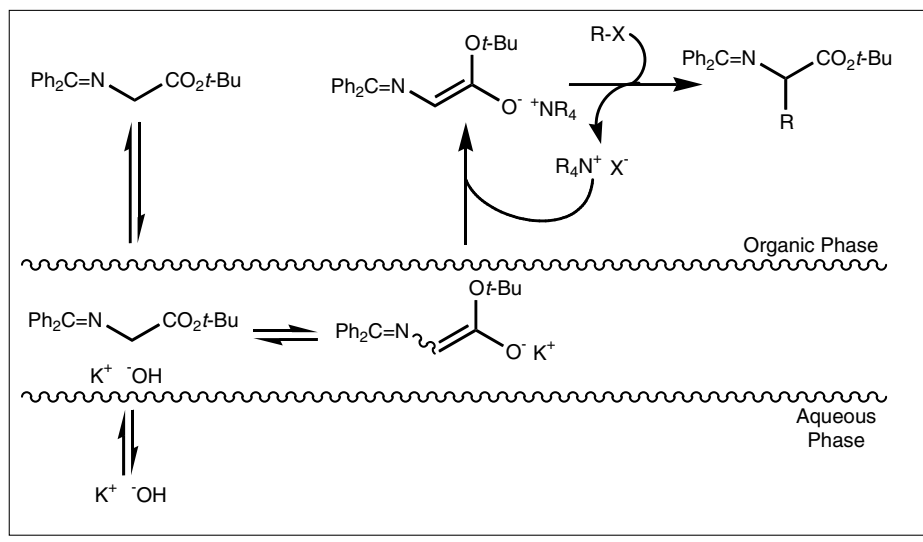

Scheme 4.

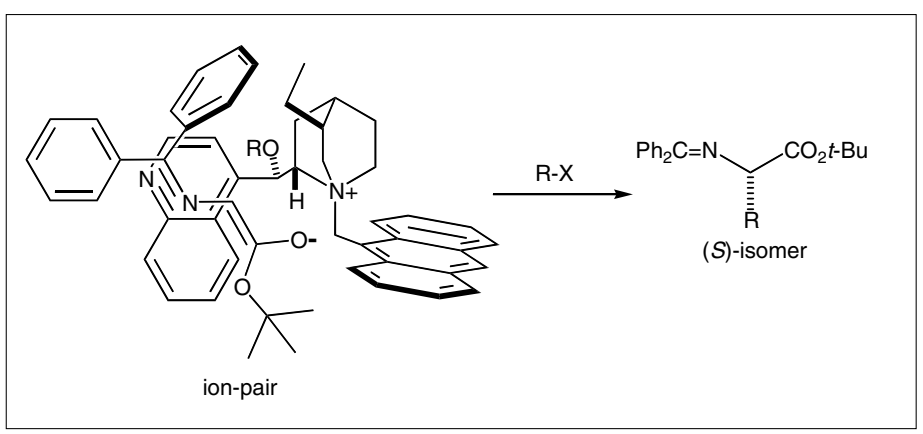

Fig. 3. Possible ion-pair arrangements for the alkylation of imine $\mathbf{1}$ with PTC 11

with the reaction proceeding via an ionpair of this type.

Overall, PTC $\mathbf{1 1}$ has proved highly effective for the alkylation of imine $\mathbf{1}$. Alkylations involving this catalyst can be performed at ambient temperature and typically result in enantioselectivities in the range 91-98\% ee. If required, it is usually possible to improve enantioselectivity by reducing the reaction temperature, ${ }^{[4,18]}$ or by fine-tuning the catalyst structure by variation of the O-alkyl substituent. ${ }^{[20,28]}$ In most instances the enantiomeric excesses can also be improved by crystallization of the products or derivatives thereof.[29,30] The utility of PTC $\mathbf{1 1}$ has now been demonstrated in the enantioselective synthesis of a wide range of $\alpha$-amino acid derivatives, ${ }^{[5,19,22,23,31-33]}$ and its ease of preparation and ease of use makes this catalyst a good choice for alkylations involving a wide range of alkyl halides.

There are of course some limitations to what can be achieved using this catalyst. For example, although some variation in the imine structure is tolerated, ${ }^{[34,35]}$ lower enantioselectivities are usually observed with esters other than tert-butyl.

\section{3. $\alpha$-Methylnaphthylamine-derived PTC 18}

Although it may well be possible to overcome the above limitations by further modification of the catalyst structure, we recently decided to investigate how easy it would be to develop a new quaternary ammonium salt PTC that could be used with other glycine imine esters. ${ }^{[36]}$ This led to the development of a $\alpha$-methylnaphthylamine- 
derived PTC 18, which has proved to be equally effective in the alkylation of imine $\mathbf{1}$, but which is more tolerant of variation in the ester moiety. ${ }^{[37]}$

Quaternary ammonium salt $\mathbf{1 8}$ can be prepared from the commercially available phenol 15 via the six-step sequence outlined in Scheme 5. This catalyst is significantly more active than cinchona-alkaloid derived catalysts such as $\mathbf{1 1}$, and this allows for lower catalyst loading to be employed. Similar observations have been reported

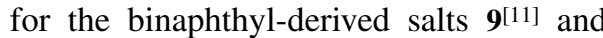
this appears to be a general feature of quaternary ammonium salts which incorporate a 6,7-dihydro-5H-dibenzo[c,e]azepinium moiety. ${ }^{[38]}$ Table 3 illustrates typical results obtained for alkylations of imine 1 using catalyst 18. ${ }^{[36]}$ Reaction times, yields and enantioselectivities are similar to those obtained with 10 mol\% PTC 11 (see Table 2), but in this case only $1 \mathrm{~mol} \%$ of the catalyst is employed.

Catalyst $\mathbf{1 8}$ has been shown to be similarly effective in the alkylation of benzhydryl ester 19 (Table 4). [37]

This opens up the possibility of generating orthogonally protected amino acid esters within a synthetic sequence, and this feature has recently been exploited in a short, stereoselective construction of the marine peptide renieramide (Scheme 6). ${ }^{39]}$

This synthesis features two asymmetric alkylation steps, the first utilizes the enantiomer of catalyst $\mathbf{1 8}$ for the enantioselective introduction of the first amino acid benzhydryl ester, and the second employs the cinchonidine-derived catalyst $\mathbf{1 1}$ to introduce an amino acid tert-butyl ester. Both of these reactions proceed with a high level of stereoselectivity, and it is also interesting to note that the first alkylation proceeds with high selectivity for the bromomethyl function.

Although there are now a wide range of catalysts and conditions that allow the highly enantioselective alkylation of glycine imines, ${ }^{[13]}$ the corresponding Michael additions have proved far more challenging and to date there have been relatively few highly enantioselective versions of this process reported. ${ }^{[40]}$ In this respect, it is notable that catalyst $\mathbf{1 8}$ is also capable of promoting Michael addition of glycine imine 19 to simple alkyl vinyl ketones. ${ }^{[41]}$ In this case the reaction is best performed under solid-liquid PTC conditions using $\mathrm{Cs}_{2} \mathrm{CO}_{3}$ as the base, and the enantioselectivity of this process is highly influenced by the nature of the organic reaction phase (Table 5).

The full scope of this chemistry is still under investigation, but preliminary studies suggest that the $\alpha$-methylnaphthylaminederived catalyst $\mathbf{1 8}$ is far more effective at promoting Michael additions than the cinchonidine derived catalyst $\mathbf{1 1}$.

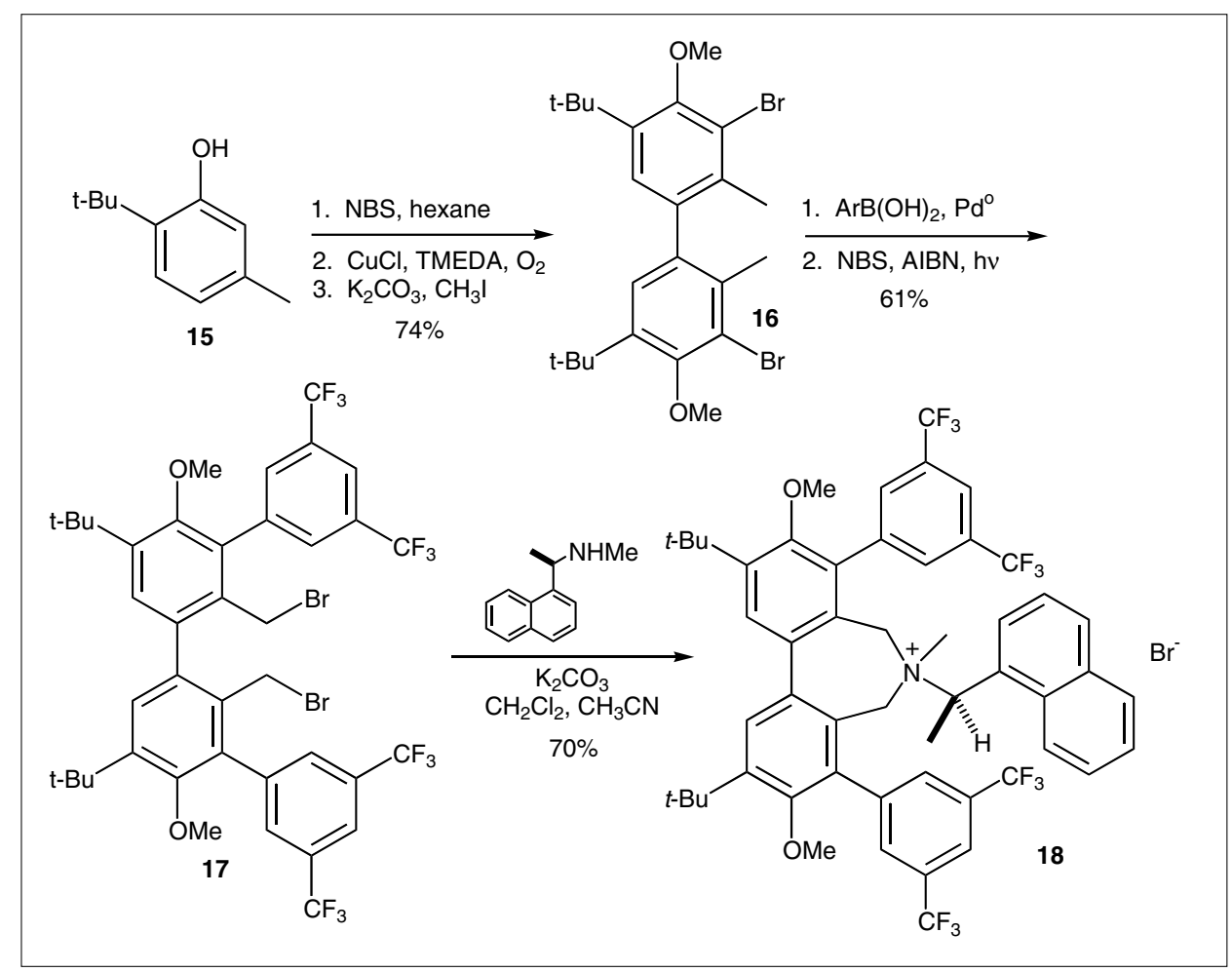

Scheme 5.

Table 3. Asymmetric C-alkylation of imine 1 using PTC 18

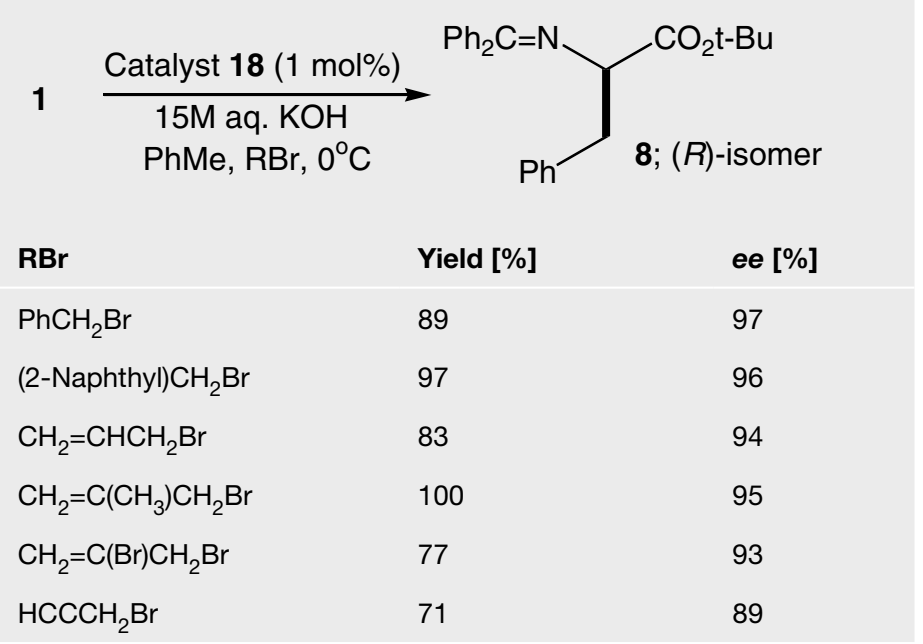

Table 4. Asymmetric C-Alkylation of imine 19 using PTC 18

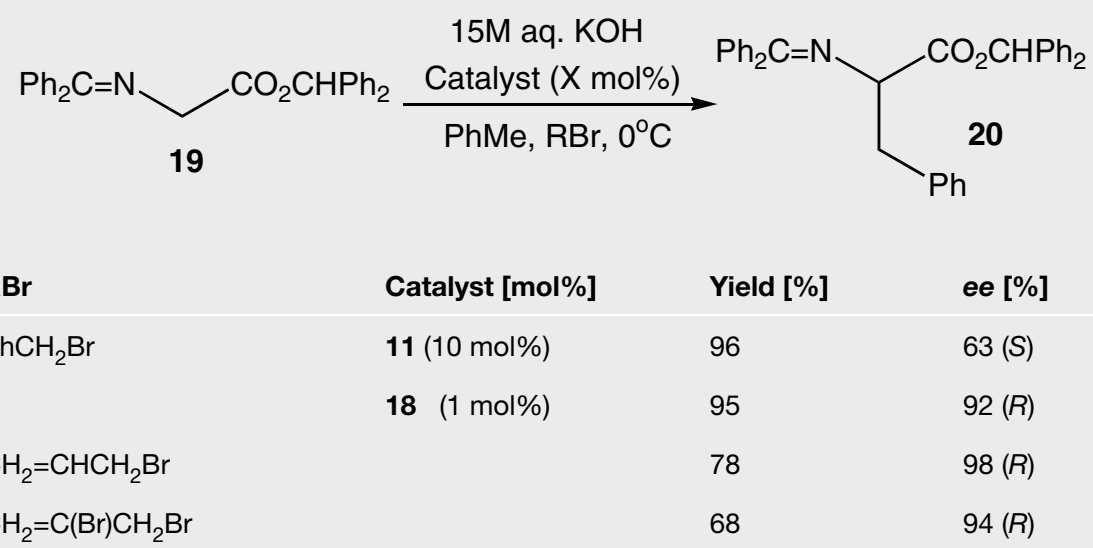




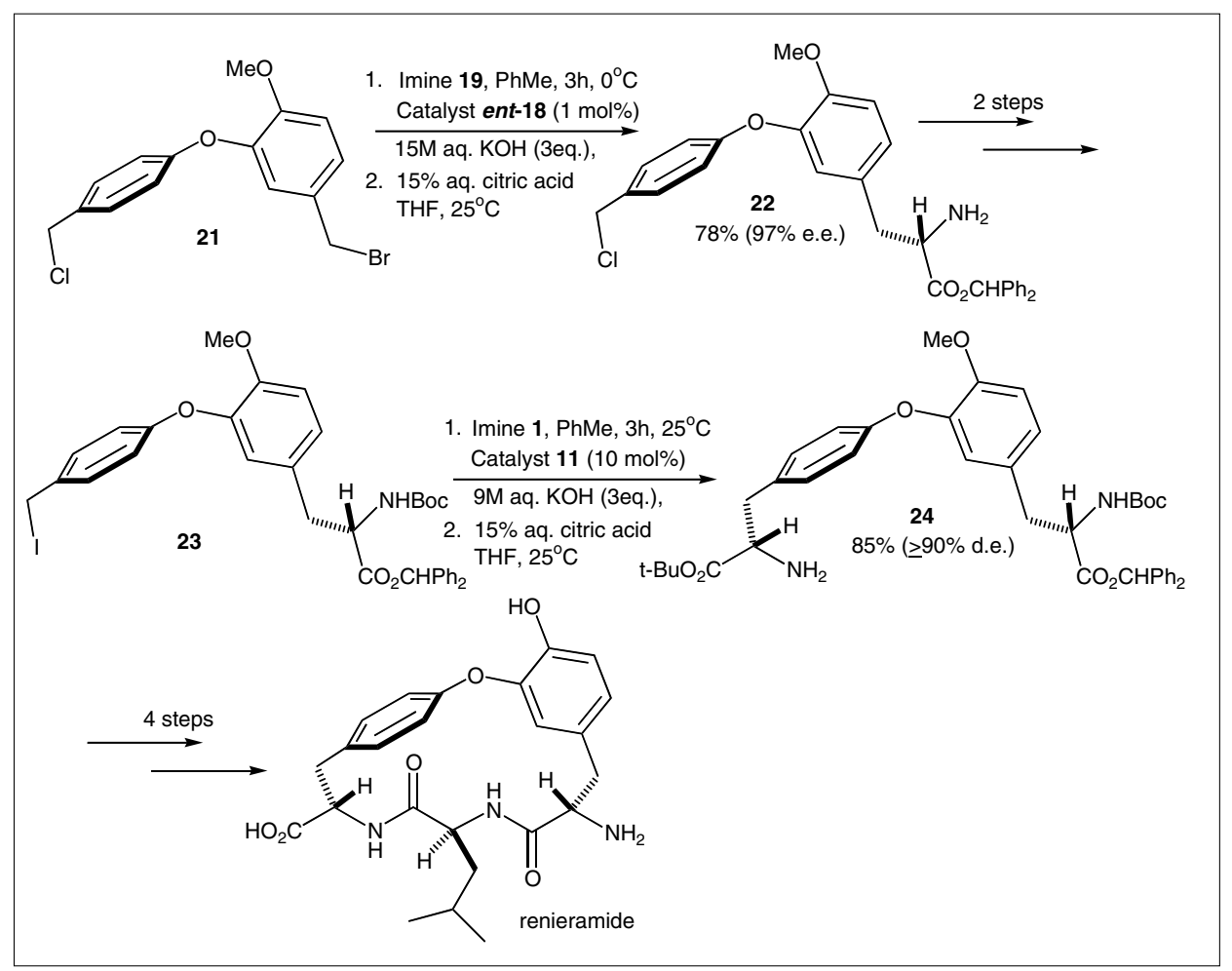

Scheme 6.

Table 5. Effect of solvent on asymmetric Michael addition of imine 19 using PTC 18

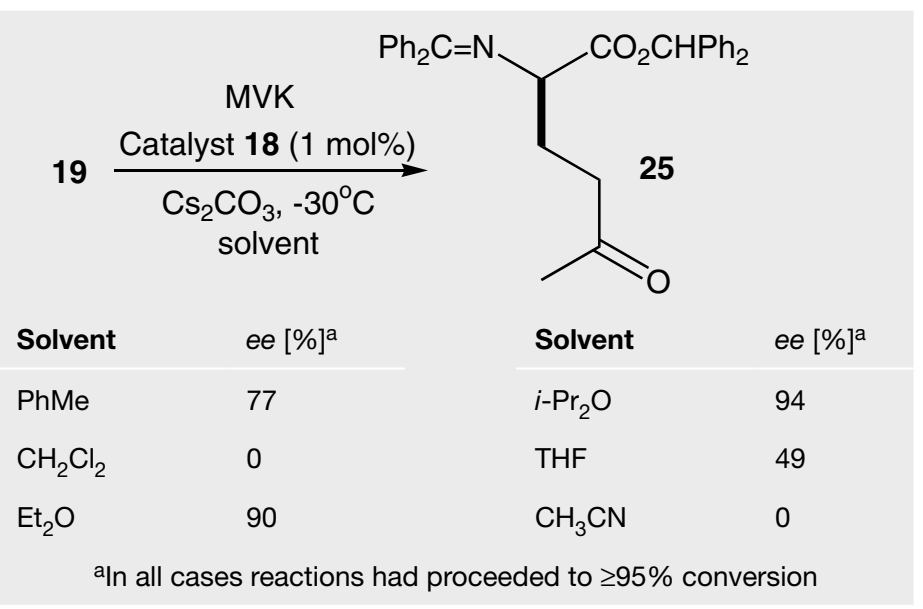

\section{Conclusion}

In this discussion we have focussed on the utility of quaternary ammonium salt PTCs $\mathbf{1 1}$ and $\mathbf{1 8}$ for the alkylation of glycine imine esters. Both catalysts are highly effective in the asymmetric alkylation of glycine imine tert-butyl esters, however, based on the studies to date, it appears that the $\alpha$-methylnaphthylamine-derived PTC 18 is substantially more versatile than the cinchonidine-derived PTC $\mathbf{1 1}$. It is also effective at significantly lower catalyst loadings, but these advantages are to some extent outweighed by the relative ease of preparation of PTC 11, and this latter aspect may persuade users to consider catalyst 11 in the first instance. These catalysts are examples of a wide range of
[1] M. J. O'Donnell, W. D. Bennett, S. Wu, J. Am. Chem. Soc. 1989, 111, 2353-2355.

[2] M. J. O’Donnell, I. A. Esikova, A. Mi, D. F. Shullenberger, $\mathrm{S}$. Wu, in ACS Symposium Series 659, 'Phase-Transfer Catalysis - Mechanisms and Syntheses', Ed. M. E. Halpern, ACS, Washington D.C, 1997, p 124; M. J. O’Donnell, S. Wu, J. C. Huffman, Tetrahedron 1994, 50, 4507.

[3] B. Lygo, P. G. Wainwright, Tetrahedron Lett. 1997, 38, 8595-8598.

[4] E. J. Corey, F. Xu, M. C. Noe, J. Am. Chem. Soc. 1997, 119, 12414-12415.

[5] B. Lygo, J. Crosby, T. R. Lowdon, P. G. Wainwright, Tetrahedron 2001, 57, 23912402; B. Lygo, J. Crosby, T. R. Lowdon, J. A. Peterson, P. G. Wainwright, Tetrahedron 2001, 57, 2403-2409.

[6] H. Yu, S. Takigawa, H. Koshima, Tetrahedron 2004, 60, 8405-8410.

[7] N. Mase, T. Ohno, H. Morimoto, F. Nitta, H. Yoda, K. Takabe, Tetrahedron Lett. 2005, 46, 3213-3216.

[8] L. Li, Z. P. Zhang, X. X. Zhu, A. Popa, S. W. Wang, Synlett 2005, 1873-1876.

[9] M. J. O’Donnell, F. Delgado, C. Hostettler, R. Schwesinger, Tetrahedron Lett. 1998, 39, 8775-8778.

[10] See for example, W. He, B. L. Zhang, W. M. Liu, X. L. Sun, S. L. Zhang, J. Chin. Org. Chem. 2006, 26, 1008-1011; M. S. Yoo, B. S. Jeong, J. H. Lee, H. G. Park, S. S. Jew, Org. Lett. 2005, 7, 1129-1131; S. Kumar, U. Ramachandran, Tetrahedron 2005, 61, 7022-7028; S. Elango, M. Venugopal, P. S. Suresh, Tetrahedron 2005, 61, 1443-1447; M. B. Andrus, Z. F. Ye, J. Q. Zhang, Tetrahedron Lett. 2005, 46, 3839-3842; R. Chinchilla, P. Mazon, C. Najera, Adv. Synth. Catal. 2004, 346, 1186-1194; R. Chinchilla, P. Mazon, C. Najera, F. J. Ortega, Tetrahedron: Asymm. 2004, 15, 2603-2607; S. S. Jew, B. S. Jeong, J. H. Lee, M. S. Yoo, Y. J. Lee, B. S. Park, M. G. Kim, H. G. Park, J. Org. Chem. 2003, 68, 4514-4516; H. G. Park, B. S. Jeong, M. S. Yoo, J. H. Lee, B. S. Park, M. G. Kim, S. S. Jew, Tetrahedron Lett. 2003, 44, 3497-3500; H. G. Park, B. S. Jeong, M. S. Yoo, J. H. Lee, M. K. Park, Y. J. Lee, M. J. Kim, S. S. Jew, Angew. Chem., Int. Ed. 2002, 41, 3036-3038; S. S. Jew, M. S. Yoo, B. S. Jeong, I. Y. Park, H. G. Park, Org. Lett. 2002, 4, 4245-4248; R. Chinchilla, P. Mazon, C. Najera, Tetrahedron: Asymm. 2002, 13, 927-931; S. S. Jew, B. S. Jeong, M. S. Yoo, H. Huh, H. G. Park, Chem. Commun. 2001, 1244-1245; H. G. Park, B. S. Jeong, M. S. Yoo, M. K. Park, H. Huh, S. S. Jew, Tetrahedron Lett. 2001, 42, 4645-4648.

[11] See for example, T. Ooi, Y. Arimura, Y. Hiraiwa, L. M. Yuan, T. Kano, T. Inoue, J. Matsumoto, K. Maruoka, Tetrahedron: Asymm. 2006, 17, 603-606; M. Kitamra, S. Shirakawa, K. Maruoka, Angew. Chem., Int. Ed. 2005, 44, 1549-1551; K. Maruoka, Pure Appl. Chem. 2005, 77, 1285-1296; T. 
Ooi, Y. Uematsu, K. Maruoka, Tetrahedron Lett. 2004, 45, 1675-1678; K. Maruoka, T. Ooi, Chem. Rev. 2003, 103, 3013-3028; T. Ooi, M. Kameda, K. Maruoka, J. Am. Chem. Soc. 2003, 125, 5139-5151.

[12] T. Ohshima, T. Shibuguchi, Y. Fukuta, M. Shibasaki, Tetrahedron 2004, 60, 7743 7754.

[13] For a recent review covering the PTC alkylation of glycine imines see, M. J. O'Donnell, Acc. Chem. Res. 2004, 37, 506-517.

[14] For general reviews covering asymmetric PTC using quaternary ammonium salts see, J. Vachon, J. Lacour, Chimia 2006, 60, 266-275; Phase-Transfer Reactions: B. Lygo, in 'Rodd's Chemistry of Carbon Compounds', Vol. V: 'Asymmetric Catalysis', 2001, Elsevier Science Ltd., Oxford, p 101-150; M .J. O’Donnell, 'Asymmetric Phase-Transfer Reactions in Catalytic Asymmetric Synthesis', 2nd Ed., Ed. I. Ojima, Verlag Chemie, New York, 2000.

[15] For recent examples of asymmetric PTC alkylation of glycine imines not covered elsewhere in this paper see, J. H. Lee, B. S. Jeong, J. M. Ku, S. S. Jew, H. G. Park, J. Org Chem. 2006, 71, 6690-6692; G. N. Grover, W. E- Kowtoniuk, D. K. MacFarland, Tetrahedron Lett. 2006, 47 , 57-60; P. V. Ramachandran, S. Madhi, L. Bland-Berry, M. V. R. Reddy, M. J. O'Donnell, J. Am. Chem. Soc. 2005, 127, 13450-13451; X. C. Chen, J. C. Chen, M. De Paolis, J. P. Zhu, J. Org. Chem. 2005, 70, 4397-4408; H. G. Park, M. J. Kim, M. K. Park, H. J. Jung, J. Lee, S. H. Choi, Y. J. Lee, B. S. Jeong, J. H. Lee, M. S. Yoo, J. M. Ku, S. S. Jew, J. Org. Chem. 2005, 70, 1904-1906; A. Okada, T. Shibuguchi, T. Ohshima, H. Masu, K. Yamaguchi, M. Shibasaki, Angew. Chem., Int. Ed. 2005, 44, 4564-4567; S. Shirakawa, K. Yamamoto, M. Kitamura, T. Ooi, K. Maruoka, Angew. Chem., Int. Ed. 2005 . 44, 625-628; Z. F. Han, Y. Yamaguchi, M. Kitamura, K. Maruoka, Tetrahedron Lett. 2005, 46, 8555-8558; A. Armstrong, J. N. Scutt, Chem. Commun. 2004, 510511; C. Lemaire, S. Gillet, S. P. Guillouet, A. Plenevaux, J. L. Aerts, A. Luxen, Eur. J. Org. Chem. 2004, 2899-2904; T. Achard, Y. N. Belokon, J. A. Fuentes, M. North, T. Parsons, Tetrahedron 2004, 60, 5919-5930; Y. N. Belokon, J. Fuentes, M. North, J. W. Steed, Tetrahedron 2004, 60, 3191-3204; M. E. Rueffer, L. K. Fort, D. K. MacFarland, Tetrahedron: Asymm. 2004, 15, 3297-3300; B. Hulin, M. G. Lopaze, Tetrahedron: Asymm. 2004, 15, 1957-1958; B. Thierry, J. C. Plaquevent, D. Cahard, Tetrahedron: Asymm. 2003, 14, 1671-1677; M. T. Allingham, A. Howard-Jones, P. J. Murphy, D. A. Thomas, P. W. R. Caulkett, Tetrahedron Lett. 2003, 44, 8677-8680.

[16] B. Lygo, B. I. Andrews, Acc. Chem. Res. 2004, 37, 518-525.
[17] B. Lygo, P. G. Wainwright, Tetrahedron 1999, 55, 6289-6300.

[18] B. Lygo, B. I. Andrews, in 'Catalysts for Fine Chemical Synthesis', Vol. 3, 'Metal Catalysed Carbon-Carbon Bond-Forming Reactions', Ed. S. M. Roberts, J. Whittall, P. Mather, P. McCormack, John Wiley and Sons, Ltd., 2004, p 27-33.

[19] B. Lygo, B. I. Andrews, Tetrahedron Lett. 2003, 44, 4499-4502.

[20] B. Lygo, B. I. Andrews, J. D. Hirst, J. L. Melville, J. A. Peterson, D. Slack, Chim. Oggi 2004, 22, 8-10; B. Lygo, B. I. Andrews, J. Crosby, J. A. Peterson, Tetrahedron Lett. 2002, 43, 8015-8018.

[21] B. Lygo, B. I. Andrews, J. Crosby, J. A. Peterson, Tetrahedron Lett. 2002, 43, 8015-8018.

[22] B. Lygo, B. I. Andrews, D. Slack, Tetrahedron Lett. 2003, 44, 9039-9041.

[23] B. Lygo, D. Slack, C. Wilson, Tetrahedron. Lett. 2005, 46, 6629-6632.

[24] M. Makosza, I. Krylowa, Tetrahedron 1999, 55, 6395-6402; H.-S. Wu, T. R. Fang, S. S. Meng, K. H. Hu, J. Mol. Cat. A: Chem. 1998, 136, 135-146; M. Rabinovitz, Y. Cohen, M. Halpern, Angew. Chem., Int. Ed. Engl. 1986, 25, 960-970; A. W. Herriott, D. Picker, J. Am. Chem. Soc. 1975, 97, 2345-2349.

[25] B. Lygo, L. D. Humphreys, Tetrahedron Lett. 2002, 43, 6677-6679.

[26] K. B. Lipkowitz, M. W. Cavanaugh, B. Baker, M. J. O'Donnell, J. Org. Chem. 1991, 56, 5181-5192; C. E. Cannizzaro, K. N. Houk, J. Am. Chem. Soc. 2002, 124, 7163-7169.

[27] B. Lygo, J. Crosby, T. R. Lowdon, P. G. Wainwright, Tetrahedron 1999, 55, 27952810; B. Lygo, J. Crosby, T. R. Lowdon, P. G. Wainwright, Tetrahedron Lett. 1997, 38, 2343-2346.

[28] J. L. Melville, B. I. Andrews, B. Lygo, J. D. Hirst, Chem. Commun. 2004, 1410-1411.

[29] M. J. O'Donnell, F. Delgado, Tetrahedron 2001, 57, 6641-6650.

[30] D. E. Patterson, S. Xie, L. A. Jones, M. H. Osterhout, C. G. Henry, T. D. Roper, Org. Proc. Res. Dev. 2007, in press.

[31] B. Lygo, J. Crosby, J. A. Peterson, Tetrahedron 2001, 57, 6447-6453; B. Lygo, J. Crosby J. A. Peterson, Tetrahedron Lett. 1999, 40, 1385-1388.

[32] B. Lygo, Tetrahedron Lett. 1999, 40, 1389-1392.

[33] E. J. Corey, M. C. Noe, F. Xu, Tetrahedron Lett. 1998, 39, 5347-5350.

[34] B. Lygo, J. Crosby, J. A. Peterson, Tetrahedron Lett. 1999, 40, 8671-8674.

[35] E. J. Corey, Y. Bo, J. Busch-Peterson, J. Am. Chem. Soc. 1998, 120, 13000-13001.

[36] J. L. Melville, K. J. R. Lovelock, C. Wilson, B. Allbutt, E. K. Burke, B. Lygo, J. D. Hirst, J. Chem. Inf. Mod. 2005, 45, 971-981; B. Lygo, B. Allbutt, S. R. James, Tetrahedron Lett. 2003, 44, 5629-5632.

[37] B. Lygo, B. Allbutt, Synlett 2004, 326328.
[38] For other examples of quaternary ammonium salt PTCs which incorporate a conformationally flexible biphenyl group, see $\mathrm{T}$. Ooi, Y. Uematsu, M. Kameda, K. Maruoka, Tetrahedron 2006, 62, 11425-11436; T. Ooi, Y. Uematsu, M. Kameda, K. Maruoka, Angew. Chem., Int. Ed. 2002, 41, 1551-1554; M. Shi, K. Kazuta, Y. Satoh, Y. Masaki, Chem. Pharm. Bull. 1994, 42, 2625-2628; M. Shi, Y. Masaki, J. Chem. Res. (S) 1994, 250-251.

[39] B. Lygo, L. D. Humphreys, Synlett 2004, 2809-2811.

[40] For examples of asymmetric PTC Michael additions involving glycine imines see $\mathrm{T}$. Shibuguchi, H. Mihara, A. Kuramochi, S. Sakuraba, T. Ohshima, M. Shibasaki, Angew. Chem., Int. Ed. 2006, 45, 4635-4637; S. Arai, F. Takahashi, R. Tsuji, A. Nishida, Heterocycles 2006, 67, 495-501; R. Chinchilla, P. Mazon, C. Najera, F. J. Ortega, M. Yus, ARKIVOC 2005, 222-232; S. Arai, K. Tokumaru, T. Aoyama, Chem. Pharm. Bull. 2004, 52, 646-648; T. Akiyama, M. Hara, K. Fuchibe, S. Sakamoto, K. Yamaguchi, Chem. Commun. 2003, 1734-1735; S. Arai, R. Tsuji, A. Nishida, Tetrahedron Lett. 2002, 43, 9535-9537; T. Shibuguchi, Y. Fukuta, Y. Akachi, A. Sekine, T. Ohshima, M. Shibasaki, Tetrahedron Lett. 2002, 43, 9539-9543; T. Ishikawa, Y. Araki, T. Kumamoto, H. Seki, K. Fukuda, T. Isobe, Chem. Commun. 2001, 245-246; M. J. O’Donnell, F. Delgado, E. Dominguez, J. de Blas, W. L. Scott, Tetrahedron: Asymm. 2001, 12, 821-828; E. J. Corey, M. C. Noe, F. Xu, Tetrahedron Lett. 1998, 39, 5347-5350.

[41] B. Lygo, B. Allbutt, E. Kirton, Tetrahedron Lett. 2005, 46, 4461-4464. 